\title{
Substantiation of Safe Conditions During Undermining of Hydraulic Waste Disposal
}

\author{
Yuriy Kutepov 1,*, Aleksandr Mironov ${ }^{1}$, Maksim Sablin², and Elena Borger ${ }^{2}$ \\ ${ }^{1}$ Saint-Petersburg Mining Institute, 199106 21-ya line, V.O., 2, St.-Petersburg, Russia \\ ${ }^{2}$ JSC SUEK-Kuzbass, 652507 ul. Vasilieva, 1, Leninsk-Kuznetsk, Kemerovo region, Russia
}

\begin{abstract}
This article considers mining and geological conditions of the site "Blagodatny" of the mine named after A.D. Ruban located underneath the old open pit coal mine and the hydraulic-mine dump. The potentially dangerous zones in the undermined rock mass have been identified based on the conditions of formation of water inflow into mine workings. Safe depth of coal seams mining has been calculated depending on the type of water body - the hydraulic-mine dump.
\end{abstract}

\section{Introduction}

Intensification of underground coal mining in the developed technical and economic areas of Kuzbass is connected with the commissioning of new sites located in close proximity to mining engineering facilities of open coal mines. This factor predetermines the emergence of conflicting geological and mechanical situations when conducting open-cast and underground mining operations in the areas of their intersection. These situations result in the development of various mining and geological processes affecting the safety of mining operations in underground and open mine workings, as well as the usage of mining structures. The greatest troubles arise when the mining operations undermine the engineering hydraulic facilities that are used for storage of hydraulic overburden, water disposal and water accumulation, such as canals, reservoirs, ponds, hydro dumps, tailing pits, sludge collectors, mine water tanks, etc. The underground coal mining carried out under them can adversely affect the stability of retaining structures - dams and dikes due to their involvement in the processes of rock movement leading to the formation of washout and the development of a hydrodynamic accident with huge environmental and economic costs, and sometimes even human casualties.

On the other hand, underground coal mining leads to a change in the structure of the undermined rock, the stress-strain state and the perviousness of rocks due to the formation of a zone of water-conducting cracks (WCZ) [3-9]. When the WCZ reaches the water body, there is a risk of flooding the mined-out area of the mines. In case of hydro dumps undermining, at the current stage of hydrogeomechanical forecasting, these water-saturated objects are considered as 'water bodies', therefore they are subject to the requirements of industrial normative and methodological documents related to assessment of the safe depth

* Corresponding author: koutepovy@mail.ru 
of underground mining. However, in fact, alluvial rock mass of these bodies is composed of plastic dispersed water-saturated sediments with low water loss and permeability. This makes it possible to revise the regulatory requirements for referring hydro dumps to "water bodies" and justifying the possibility of their undermining.

\section{Description of the study objects}

The assessment of the possibility of conducting underground mining operations at the site "Blagodatny" was carried out for the conditions of A.D. Ruban Mine in Leninsk-Kuznetsk, which plans to extract the coal reserves lying under the hydro dump in the mine working of Krasnogorsky-11 site of the Mokhovsky coal pit branch. Within the mine take area, two types of rocks are distinguished: man-made (alluvial and fill-up) and natural coal-bearing strata. The coal-bearing strata is represented by an alternation of thick layers of sandstones and siltstones with coal seams and coal partings. Its upper part to the depth of 40-50 m from the surface of the bedrock is weathered and has an increased rock fracturing. It is planned that the site "Blagodatny" will mine coal seams Polysaevskiy II, Nadbaikaimskiy and Baikaimskiy with average capacities of $4.7 \mathrm{~m} ; 2.8 \mathrm{~m}$ and $2.9 \mathrm{~m}$ respectively. The hydrogeological conditions of the site are characterized by the development of aquifers in the upper near-surface part of weathered bedrock and alluvial sediments.

The hydraulic dump in the mine workings of Seam Krasnogorskiy II is rated as Class 1 according to the design and consists of the following: alluvial rock strata that was created in the reservoir (cup) of the space mined out by hydraulic method from overburden rocks of the Neogene-Quaternary age; three levees built of technogenic overburden rocks of the Mokhovsky open-pit mine; systems of slurry-haul and recycled water supply. The maximum thickness of the alluvial rocks is up to $60 \mathrm{~m}$, they are characterized by a heterogeneous structure in composition and consistency in plan and in section. The alluvial strata is divided into zones of sand-sandy loam, loamy sail and argillaceous rock. Within each of the zones there are sub-zones of flow, plastic and stiff rocks $[1,2,10]$. The thickness of the flowing rocks varies from $10 \mathrm{~m}$ to $25 \mathrm{~m}$.

\section{Justification of the possibility to develop and mine seams under the hydraulic dump}

The analysis of the mining and geological conditions of the site allows you to identify potentially hazardous areas where mining operations may be accompanied by water seepage. These hazardous areas include the near-surface aquifer of groundwater, confined to the weathered zone of bedrock, and also the water-saturated thickness of the alluvial sediments of the hydraulic dump. It can be assumed that the near-surface aquifer formed in the weathered rock is characterized by low filtration properties, apparently due to the calmatation of the fissures by the clay material during filling of the hydraulic dump. The alluvial rocks are also characterized by low water transmissivity as they are represented by argillaceous deposits. These circumstances open up the prospect for a successful undermining of the selected water bodies (hazardous areas).

However, despite the highlighted favorable factors, the hydro dump at this stage of exploration should be considered as the "water body" under which underground mining is planned. The assessment of safe mining conditions in this case is carried out in accordance with the current "Regulations for the protection ..." [3] beginning with the definition of the type of the given water body. The justification of the type of water body is carried out on the basis of information on thickness, material composition, physical-mechanical and filtration properties of the bottom sediments and the rocks of the foundation of the undermined water body. Since no special studies were carried out to study the structure, state and properties of the hydro dump, it is only possible now, before their implementation, to estimate the safe 
development of the seam formation under the hydro dump on the basis of the existing longterm experience of studies of the Kuzbass hydro dumps.

It should be noted that, depending on the classification of the water body (hydro dump) in relation to a particular type (group), the safe depth of mining along the Polysaevskiy II seam can vary widely. In this case, the location of the hydro dump on a water-conducting base which has a hydraulic connection with the zone of active water exchange (zone of fracturing) in the bedrock should be considered as extremely unfavorable conditions. In this option, the hydro dump and the near-surface aquifer confined to the zone of free water exchange in the fractured bedrock form a single aquifer system. The boundary of the zone of free water exchange in the weathered bedrocks lying at a depth of $130 \mathrm{~m}$ from the surface should be taken for the lower boundary of the undermined water body, from which the safe depth is measured. At an average seam extraction thickness $\mathrm{m}_{1}=4.7 \mathrm{~m}$ and the ratio of the total thickness of mudstones and siltstones lying under the water body to the thickness of the undermined rock mass more than 0.4 according to paragraph 6.8 of the "Regulations ...", the safe depth of the Polysaevsky II seam is: $H_{\text {safel }}=40 \times m_{1}=40 \times 4.7=188 \mathrm{~m}$

The minimum depth of the upper seam Polysaevskiy II under the water body within the site is $120 \mathrm{~m}$, therefore it is inadmissible to mine it without carrying out certain mining measures related to the decrease in the safe depth (Fig. 1). At the same time, when they are mined together, the Nadbaikaimskiy and Baykaimskiy seams lying below along the section of the coal-bearing strata have the calculated safe depth $\left(\mathrm{H}_{\text {safe }(2+3)}\right)$ which does not reach the lower contour of the undermined water body (see Figure 1). These conditions make it possible to mine them out in descending order in a sequential or joint manner.

The most promising in terms of safe mining of the considered formation of layers is the option, which assumes that dense sediments with a capacity of at least $10 \mathrm{~m}$, identical in filtration properties to water-resistant clays, are formed on the bottom of the hydro dump. In this case, this water body belongs to group II, and the bottom of the hydro dump can be taken for its lower boundary. In accordance with clause 6.8 of the "Regulations ...", the safe depth for the Polysaevsky II seam should be estimated based on the following relation: $H_{\text {safel }}=20$ $\times m_{l}=20 \times 4,7=94 \mathrm{~m}$.

This value of the safe depth for mining the upper seam opens the possibility of its full excavation under the hydro dump (Figure 1) without carrying out certain mining measures.

The above calculations were carried out in accordance with the normative and methodological document in force in the coal industry, which regulates the use of a "waterconducting cracks zone " (WCZ) equal to $40 \mathrm{~m}_{1}$ in the first option [3]. However, in real conditions of coal deposits, the area of WCZ may be less, and sometimes even larger [3-9]. It depends, in many respects, on deformation behavior and the physical and mechanical properties of the mined rocks. The engineering geological conditions of the LeninskKuznetsk coal mines that mine the coal seams of the Kolchuginskaya series are characterized by the presence of coal-bearing rocks of a low degree of metamorphism corresponding to D coal grade. These rocks have clay cement, not high strength and deformation properties, so it can be assumed that the WCZ zones when they are undermined by underground mine workings will be less than the normative value.

\section{Water-Conducting Cracks Zone}

In 2018, in mining the first longwall in the "Magistralny" area, a surveying and hydrogeological station was installed to study the processes of shifting and formation of WCZ induced by initial undermining. At present, the longwall is not fully mined out, the monitoring continues. The analysis of the current observations gives grounds to assume that the size of the WCZ in the roof of the mined Polysaevsky II seam will be less than $26 \mathrm{~m}=$ 
$124 \mathrm{~m}$. The preliminary assessment of the safe water body mining depth makes it possible to recommend the upper seam Polysaevsky II for mining irrespective of the properties of the alluvial rocks and the location of the water body boundary. Accordingly, the bottom two seams with such a parameter of WCZ can be safely mined without any restrictions.

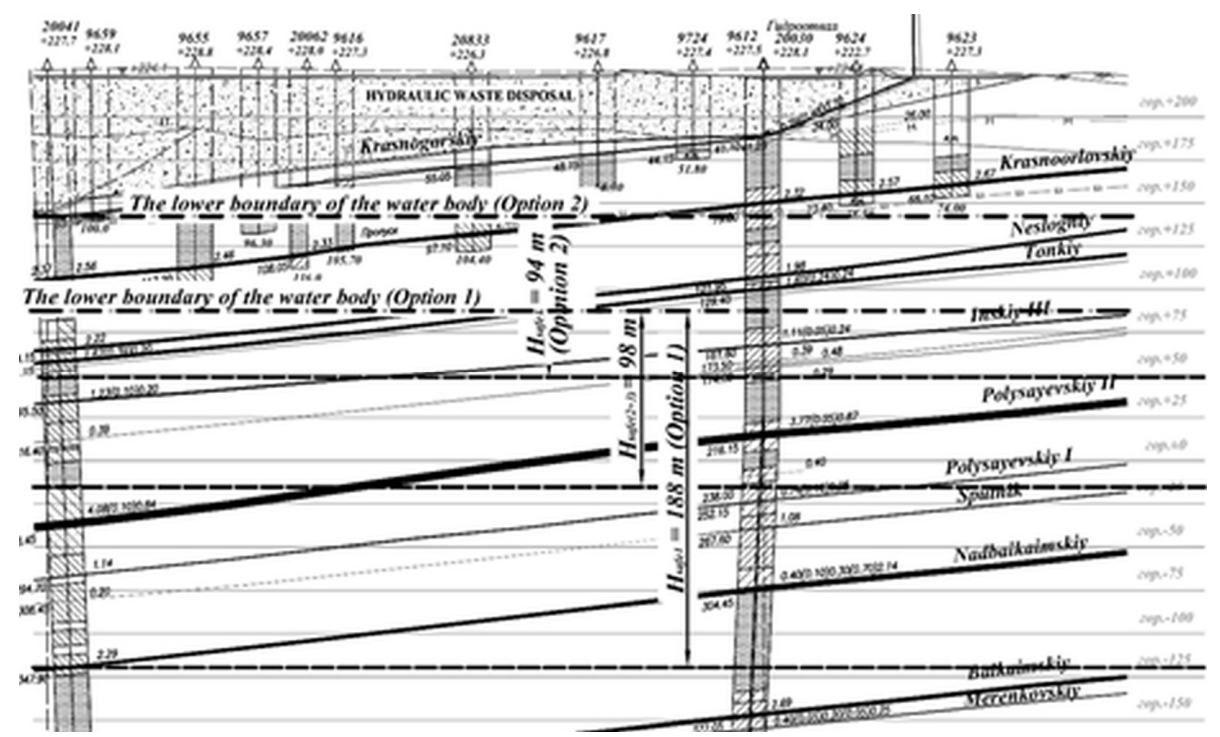

Fig. 1. Geological section along the exploration line with the design boundaries of the water body (in two options) plotted thereon, as well as safe mining depths for seam Polysaevskiy II ( $\left.\mathrm{H}_{\text {safel }}\right)$ (in two

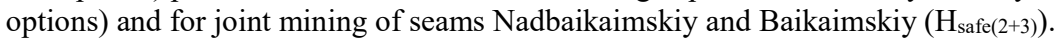

\section{Conclusions}

Summarizing the results of the justification of the safe depth for underground mining of the coal seams beneath the hydro dump, we would like to emphasize the great relevance of this issue not only for the conditions of the mines of the city of Leninsk-Kuznetsk, but for other coal and ore deposits mined underground. Unfortunately, the issue of ensuring the stability of the hydro dump when it is undermined by underground mining operations due to the limited volume of the article was left out of consideration. This is a large and independent study addressing the issues of rock movement and the stability of slopes of hydraulic structures.

\section{References}

1. Yu. I. Kutepov, N. A. Kutepova, Geoecologia, 5, 405-413 (2003)

2. Instructions on the methods of hydrogeomechanical justification of optimal parameters of hydro dumps and dumps on weak grounds. Part II. The rationale for the optimal parameters of the dumping structures (VNIMI, Leningrad, 1998)

3. Regulations for the protection of structures and natural objects from harmful influence of underground mining in coal deposits (Nedra, Moscow, 1981) 
4. V. N. Gusev, A. S. Mironov, D. A. Ilyukhin, The method for determining the height of the zone of water-conducting cracks over the mined out space in the reservoir deposits Patent No 2477792. 20.03.2013, No 8 (Rospatent, Moscow, 2013)'

5. Yu. I. Kutepov, N. A. Kutepova, M. A. Karasev, A. D. Vasilieva, Hydrogeomechanical processes in development of spoil dumps and hydraulic fills (EUROCK 2018, Saint Petersburg, 2018)

6. V. V. Zubkov, I. A. Zubkova, Zones of technogenic water-conducting cracks by roomand-pillar mining (EUROCK 2018, Saint Petersburg, 2018)

7. V. V. Zubkov, I. A. Zubkova, International Research Journal, 2.05(59), 172-175 (2017)

8. V. N. Gusev, Geomechanics of technogenic water-conducting cracks (Mining, St.Petersburg, 1999)

9. A. G. Akimov, Geomechanical aspects of rock subsidence due to underground development of coal and ore deposits (Mining, St.-Petersburg, 2013)

10. A. M. Galperin, Hydrogeology and Engineering Geology: Geotechnika - Selected Translations of Russian Geotechnical Literature (CRC Press, New York, 2003) 